\title{
ENFOQUE COOPERATIVO Y CUSTODIA DEL TERRITORIO: DOS FACTORES IMPULSORES DE LA TRANSICIÓN AGROECOLÓGICA DE LOS SISTEMAS AGROALIMENTARIOS LOCALES
}

\author{
Carolina Yacamán-Ochoa \\ Departamento de Geografía, Universidad Autónoma de Madrid \\ carolina.yacaman@uam.es \\ ORCID Id: https://orcid.org/0000-0003-1258-0498
}

\author{
Marina García-Llorente \\ Laboratorio de Socio-Ecosistemas, Departamento de Ecología, Universidad Autónoma de Madrid \\ marina.gllorente@uam.es \\ ORCID Id: https://orcid.org/0000-0002-3527-9318
}

Recibido: 04/02/2020; Aceptado: 13/08/2020.

Cómo citar este artículo/citation: Yacamán Ochoa, Carolina y García Llorente, Marina (2020). Enfoque cooperativo y custodia del territorio: Dos factores impulsores de la transición agroecológica de los sistemas agroalimentarios locales. Estudios Geográficos, 81 (289), e050. https://doi.org/10.3989/estgeogr.202064.064

RESUMEN: Los cambios experimentados desde mediados del siglo XX, como consecuencia de la industrialización de la agricultura, han favorecido la desconexión entre la producción de alimentos, la naturaleza y la sociedad. Esto nos sitúa frente a una serie de retos socio-ecológicos que necesitan ser resueltos para frenar la crisis de la agricultura de pequeña escala y el deterioro de los agroecosistemas. En contraposición a las lógicas que deslocalizan la producción del consumo y que rompen el vínculo con el territorio, diversas iniciativas están integrando prácticas crecientemente agroecológicas y adaptando sus formas de comercialización hacia modelos más sostenibles y territorializados. Con la necesidad de identificar las estrategias transformadoras en que los agricultores avanzan para crear sistemas alimentarios sostenibles, se analizan dos estudios de caso exploratorios en España (Extremadura y Asturias). Los resultados muestran cómo los enfoques cooperativos, las redes colaborativas enraizadas en el territorio y los acuerdos voluntarios de colaboración que se establecen entre diferentes agentes del sistema agroalimentario son factores clave para permitir a los pequeños productores mejorar su participación y empoderamiento en el sistema agroalimentario, a la vez que se fomentan estrategias sistémicas para cambiar los modos de producción y consumo hegemónicos.

PALABRAS CLAVE: agricultura de pequeña escala, agroecología, gobernanza cooperativa, servicios de los ecosistemas agrarios, innovación social, custodia del territorio.

\section{COOPERATIVE APPROACH AND LAND STEWARDSHIP: TWO DRIVERS FOR THE AGRO- ECOLOGICAL TRANSITION OF AGRI-FOOD SYSTEMS}

ABSTRACT: The changes experienced since the mid-20th century because of the industrialization of agriculture, have favored the disconnection between food production, nature and society. This places us in front of a series of socio-ecological challenges that need to be solved in order to stop the crisis of small-scale agriculture and the deterioration of agro-ecosystems. In contrast to the logics that delocalize production from consumption, breaking the link with the territory, various initiatives are integrating increasingly agro-ecological practices and adapting their forms of commercialization towards more sustainable and territorialized models. With the need to identify the transformative strategies in which farmers are advancing to create sustainable food systems, two case studies in Spain (Extremadura and Asturias) are analyzed. The results show how cooperative approaches, collaborative networks rooted in the territory and voluntary agreements established between different agents in the agri-food system, are key factors in enabling small producers to improve their participation and empowerment in the agri-food system while promoting systemic strategies to change hegemonic production and consumption modes.

KEY WORDS: small-scale agriculture, agro-ecology, cooperative governance, agricultural ecosystem services, social innovation, land stewardship.

Copyright: ( 2020 CSIC. Este es un artículo de acceso abierto distribuido bajo los términos de la licencia de uso y distribución Creative Commons Reconocimiento 4.0 Internacional (CC BY 4.0). 


\section{INTRODUCCIÓN}

Los procesos de restructuración productiva asociados a la intensificación ${ }^{1}$ y la especialización ${ }^{2}$ de la agricultura en Europa desde mediados del siglo XX se han logrado a expensas de la agricultura de base campesina, de fragmentar su organización social y de privatizar y limitar el acceso a los bienes comunes. Globalmente, las estrategias de la Revolución Verde se promovieron sin ninguna consideración hacia los contextos culturales o ecológicos locales, mientras que su aplicación requería suministros crecientes de insumos y la expansión de los mercados globales de materias primas. Esto creó una dependencia de los agricultores, tanto en sus vínculos progresivos como regresivos (Sevilla y Woodgate, 2013, p.30). En definitiva, la industrialización agrícola ha generado altos costes territoriales entre el campo y la ciudad, incrementando la polarización entre zonas de producción y de consumo y provocando la ruptura del equilibrio de los sistemas ecológicos (Matson, Parton, Power y Swift, 1997; Tilman, 1999; Cumming et al., 2014).

En este contexto, la financiarización del sistema agroalimentario ha reforzado la posición de las grandes distribuidoras como actores dominantes, erosionando el poder de los pequeños agricultores en relación con otros actores de la cadena alimentaria; se han deteriorado sus rentas mientras han aumentado las cargas de trabajo (Ryan Isakson, 2014). Para ejemplificar esto, en los últimos 20 años en Europa, el tamaño de las fincas se ha incrementado mientras que su número ha continuado decreciendo, en especial, por los ajustes estructurales fomentados por la Política Agraria Común (subsidios proporcionales a las superficies de las fincas) (Franco y Borras, 2015; EUROSTAT, 2019). Este proceso ha hecho que los agricultores sean más dependientes del mercado y de nuevas tecnologías para alcanzar un umbral de ingreso mínimo. En otras palabras, son más dependientes del complejo agroindustrial en su conjunto (González de Molina, 2013). Como resultado, se están desarticulando los sistemas de agricultura campesina debido a la transformación de las relaciones de poder a lo largo del sistema agroalimentario.

La primera consecuencia de la industrialización de la agricultura a escala local/regional es la desestructuración de las relaciones de proximidad espacial y organizativa entre los agentes de la cadena alimentaria. Este problema dificulta la posibilidad de vincular la narrativa histórica y la cultura del lugar a la producción de los alimentos allí donde fueron cultivados, cuestión que resulta esencial para diferenciar los alimentos tradicionales de aquellos producidos en masa y a distancia (Yacamán et al, 2020a). A escala de paisaje o de agroecosistema, como señalan González de Molina et al., (2019), "la industrialización ha traído consigo una segregación creciente de los usos del suelo y la pérdida de sinergias productivas y funcionales que generaba la integración agrosilvopastoril" (2019, p.117). En definitiva, se está perdiendo la calidad y heterogeneidad de los paisajes agrarios tradicionales y se está intensificando la ruptura de los equilibrios ecosistémicos previos.

A partir del comienzo de la industrialización de la agricultura, el papel de las actividades agrarias en el metabolismo entre sociedad y naturaleza también se ha modificado (Infante y González de Molina, 2013). La creciente tendencia hacia la especialización e intensificación productiva de los agroecosistemas, que son el tipo de ecosistema más representativo de España ha provocado el deteriorado los servicios de los ecosistemas en términos de cantidad y calidad. Se han reducido el suministro tanto de los servicios de abastecimiento (ej. a través del alimento procedente de la agricultura y la ganadería y el mantenimiento del acervo genético con variedades locales y razas ganaderas), servicios de regulación (ej. almacenamiento de carbono, regulación hídrica, polinización, y hábitat para la biodiversidad) y culturales (ej. conocimiento local, recreación, sentido de pertenencia, etc.). Según la Evaluación de Ecosistemas de España (EME, 2011), en los últimos 50 años, el 68\% de los servicios de los ecosistemas evaluados muestran una situación preocupante como consecuencia del abandono, la intensificación, la contaminación y el cambio de ciclos biogeoquímicos. En particular, la actividad agraria tiene un efecto directo en la conservación de éstos. Cuando las practicas realizadas no van en aras de la conservación, pueden provocar importantes trade-offs o contrapartidas; favoreciendo la obtención de servicios de abastecimiento con valor productivo en los mercados a costa de un deterioro en los servicios de regulación y culturales (Zhang et al., 2007). Como resultado, existe una creciente preocupación de gestionar paisajes agrarios que sean: i) multifuncionales; ii) que suministren bienes públicos agroambientales; iii) y que sean cultivados de manera sostenible mediante manejos agroecológicos (Swinton et al., 2007; Gordon et al., 2010; García-Llorente et al, 2012).

Como alternativa radicalmente crítica al paradigma productivista, el enfoque agroecológico se empieza a 
consolidar como marco para el diseño y manejo de ecosistemas agrícolas sostenibles (Altieri, 2009; González de Molina, 2013; Duru et al., 2015; Lamine et al., 2015; Anderson et al., 2019). La agroecología es una disciplina científica, un conjunto de prácticas y un movimiento sociopolítico que responde a los impactos del modelo agrario industrial, desde un enfoque teórico y aplicado mediante el uso de diversas estrategias colectivas. La cooperación realizada mediante acciones colectivas puede dar a los pequeños productores la posibilidad de competir y posicionarse en los mercados (Meinzen-Dick et al., 2009). Desde esta perspectiva emergente, se observa que las prácticas asociadas a la agroecología tienen un carácter transformador que implica el rediseño de todo el sistema agroalimentario (Tittonel, 2014), en el que se integran las complejas relaciones que se establecen entre funcionamiento ecológico, bienestar humano, innovación, modelos de gobernanza y políticas bottom-up. De esta manera, la agroecología imprime la visión socio-ecológica al contexto de los agroecosistemas (García-Llorente et al., 2019; Oteros-Rozas et al., 2019). Desde esta aproximación, estudios recientes señalan un cambio de paradigma científico para abordar el sistema agroalimentario desde enfoques teóricos sectoriales hacia enfoques sistémicos apoyados en procesos de toma de decisiones ligados a la gobernanza territorial. Desde una perspectiva holística, la agroecología considera que los problemas del sistema agrario no pueden ser estudiados con independencia de las comunidades humanas y los contextos sociales en los cuales se sitúan (Wibbelmann et al., 2013). En este sentido, la agroecología tiene entre sus principios esenciales hacer partícipes a todos los actores implicados para el rediseño del sistema agroalimentario local (Hatt et al., 2016).

En este artículo profundizamos desde el enfoque de la agroecología en el estudio de los procesos sociales que están permitiendo a los pequeños productores llevar a cabo cambios estructurales que contribuyen a crear sistemas agroalimentarios más sostenibles de producción, distribución y consumo, mediante el fomento de una agricultura territorializada y multifuncional. En particular, nos interesamos en conocer los factores que fomentan o dificultan el desarrollo de la innovación a partir de enfoques participativos bottom-up. La hipótesis que guiará esta investigación es la planteada por Swagemakers et al., (2019), que señalan que las estructuras de autogobierno enraizadas en el territorio, que se organizan para gestionar sus propios recursos según sus propios valores y normas, juegan un papel esencial para me- jorar beneficios tangibles e intangibles a diferentes escalas del sistema agroalimentario en su conjunto. Finalmente, a modo de conclusión se llama la atención sobre la necesidad de mejorar las estrategias de innovación social para crear soluciones duraderas y efectivas que aumenten el valor añadido y mejoren la conservación de los servicios de los ecosistemas agrarios.

\section{PUESTA EN PERSPECTIVA DE LA INNOVACIÓN SOCIAL PARA AVANZAR HACIA LA TRANSICIÓN AGROECOLÓGICA}

Diversos autores proponen que la innovación social debe tener un mayor protagonismo en las estrategias para favorecer un desarrollo rural integrado (Di lavoco et al., 2014; Neumeir, 2012 y 2017; Bock, 2016) y, más recientemente, para fortalecer la transición agroecológica del sistema agroalimentario a escala territorial (Yacamán et al., 2020a; Yacamán et al., 2020b). La innovación social tiene diversas definiciones y enfoques teóricos. En el marco de esta investigación, nos interesa el enfoque señalado por Neumeir (2012) que destaca el potencial de la innovación fuertemente vinculado con la existencia de redes sociales y del capital social disponible a escala local, así como que el desarrollo de la innovación social va mucho más allá de los avances tecnológicos y se enfoca en el cambio de actitudes y comportamientos de un grupo de personas organizadas en una red con intereses similares, que conduce a nuevas y mejores formas de acción colectiva que fuera de él.

\section{Las redes económicas alternativas y el enfoque cooperativo}

La aproximación teórica sobre el análisis de las redes económicas alternativas, que buscan superar las contradicciones y los conflictos asociados a los procesos de globalización en el campo agroalimentario, son crecientes (Méndez, 2018; Méndez y Monteserín, 2017; Sánchez, 2009; Michelini et al., 2017). En concreto, las redes económicas alternativas se definen como" el conjunto de prácticas relacionadas bien con la producción, el intercambio, el consumo o la financiación, que cuestionan de algún modo la racionalidad hegemónica -ya sea la lógica capitalista en su conjunto, o la manifestación específica de la globalización neoliberal" (Méndez, 2018, p. 8-9). Por el contrario, son redes que defienden una economía donde prevalecen los valores como la solidaridad, la demo- 
cracia, la reciprocidad, la inclusión y la sostenibilidad. Esta definición evidencia que este tipo de redes excluyen las soluciones puras basadas en el mercado y las de carácter jerárquico y, por el contrario, se basan en procesos de cooperación en un entorno construido socialmente (Thompson, 2003). En definitiva, la confianza se convierte en el principal mecanismo de dinamización creado a partir de elementos como la proximidad, la autogestión, el intenso compromiso político y la búsqueda de soluciones mutuas para satisfacer necesidades económicas y socioambientales concretas en la escala local (Sánchez y Espinosa, 2020).

Un aspecto importante en el debate y reflexión sobre el potencial que pueden tener estas redes para favorecer la transición hacia sistemas agroalimentarios más sostenibles radica en identificar los factores que influencian el éxito o limitan la innovación social. Méndez (2016) destaca la importancia de que tenga lugar una proximidad espacial entre los actores de la innovación que permite mejorar el conocimiento y reconocimiento mutuo, que es la base para establecer relaciones de reciprocidad sustentadas en cierto grado de confianza mutua, que facilitarán el intercambio de conocimiento tácito y no codificable. Para Moulaert et al. (2005), mejorar el empoderamiento de las comunidades y la capacidad organizativa de la sociedad civil son otros elementos determinantes para satisfacer las necesidades humanas y para movilizar recursos que fortalezcan la economía local.

En este mismo sentido, Davies et al. (2012) señalan que es necesario que las redes movilicen el potencial endógeno para favorecer la identidad local, tanto para impulsar el desarrollo regional como el desarrollo endógeno. Para Caravaca (2017), el éxito de estos procesos se ve fortalecido mediante el impulso de iniciativas de carácter colectivo y comunitario que facilitan diferentes formas de generación de la creatividad social y el conocimiento colectivo para resolver algunos de los retos actuales. Asimismo, según Méndez y Monteserín (2019), desde la dimensión política, las redes que se construyen en oposición al paradigma productivista de la agricultura deben impulsar procesos emancipadores en la escala local que vayan más allá de la resistencia o la protesta frente a las injusticias del sistema.

Como destaca Neumeir (2017), aunque hay bastantes factores individuales que influyen en el éxito de los procesos participativos, resulta más interesante identificar un subconjunto de factores que mejoran las posibilidades de éxito de la innovación social. Una serie de estudios recientemente publicados identificaron un conjunto de estrategias que favorecen estructuras organizativas en red que son espacialmente importantes para mejorar la escalabilidad de los circuitos cortos alimentarios y resolver carencias de tipo logístico y organizativo de pequeños productores (Yacamán et al., 2020a): i) promover la gobernanza interna entre pequeños productores y fomentar relaciones estables basadas en la confianza para reducir la competencia y combatir el aislamiento; ii) generar procesos sistémicos orientados a satisfacer carencias o necesidades socioeconómicas ciudadanas vinculadas con el alimento y no solamente con la creación de nuevos productos e ideas para reducir la desconexión entre agricultura, medio ambiente y sociedad; iii) estimular interacciones directas con el comercio minorista, el sector de la restauración y la compra pública para relocalizar el sistema agroalimentario; iv) favorecer el impulso creativo y la diferenciación de los productos locales con atributos específicos (ecológico, local, de temporada, variedades locales, artesanal) para mejorar el valor añadido; v) dinamizar comunidades de aprendizaje y la transferencia continua de conocimiento entre actores múltiples; vi) impulsar el trabajo en red entre pequeños productores para incrementar el poder de negociación; vii) activar la identidad de cada territorio, de sus paisajes, la acumulación histórica de saberes, agentes y recursos endógenos para poner en valor procesos de reterritorialización; viii) mejorar la eficiencia energética, ambiental y económica de los procesos en las distintas fases de la cadena alimentaria mediante el intercambio de recursos y servicios en favor de la transición de un sistema agroalimentario; ix) apoyar la capacitación en las buenas prácticas agrarias para avanzar hacia la transformación agroecológica de la agricultura; x) por último, convertir la proximidad geográfica campo-ciudad en una oportunidad para reducir costes energéticos y económicos asociados al transporte.

Todas las respuestas mencionadas constituyen ventajas alternativas que permiten integrar las especificidades y el carácter de un territorio concreto en el valor añadido de los productos locales, así como optimizar la eficiencia en los circuitos cortos alimentarios; también son de interés para estimular el conocimiento y las habilidades de pequeños productores que permitan construir una alternativa sólida a las formas de distribución dominante de las grandes áreas urbanas. Son estrategias cooperativas indispensables para favorecer un modelo de producción y consumo territorialmente más sostenible y social y 
económicamente más justo. Se pone así en evidencia la doble aportación del enfoque cooperativo y de las redes económicas alternativas para fortalecer los aspectos organizativos de los pequeños productores y aumentar su potencial transformador.

\section{Acuerdos de custodia del territorio}

Los enfoques emergentes para mejorar el suministro de los servicios de los ecosistemas y la conservación de la biodiversidad en los paisajes agrarios se están orientando a promover estrategias de gobernanza territorial para favorecer la agricultura multifuncional (Groenfeldt, 2006). Para asegurar la producción de múltiples servicios de los ecosistemas a escala de paisaje, se recomienda elaborar estrategias integradas que tengan en consideración los procesos ecológicos, las prácticas agrarias culturales y las estructuras sociales de los territorios (Vialatte et al., 2019). A su vez, estos autores destacan la importancia de comprender y fortalecer las interacciones entre diversos agentes, entre los que destacan los agricultores, los consumidores y los dirigentes políticos en la escala local-regional. Por ello, para alcanzar estos objetivos se requiere no sólo que las explotaciones agrarias adapten sus manejos en torno a producciones de alimentos ecológicos, sino que además resulta necesario contar con el apoyo de múltiples agentes (representantes institucionales, planificadores y gestores del territorio, entidades conservacionistas, agentes económicos, consumidores, redes alimentarias alternativas, etc.), implicados en diferentes niveles organizativos y escalas geográficas.

Debemos tener en consideración que los agroecosistemas son el resultado de las interacciones humanas con el medio ambiente y que su gestión condiciona en buena medida la capacidad futura del suelo para producir alimentos y la posibilidad de seguir proporcionando a la sociedad múltiples beneficios (Horrigan et al., 2002). Es, por lo tanto, necesario reflexionar sobre iniciativas concretas a escala de finca y de paisaje. A su vez, interesa mejorar la gestión de un paisaje agrícola con diferentes tipos de cultivos y con diferente organización espacial característica de los mosaicos de cultivos tradicionales para proporcionar servicios de los ecosistemas más diversos. A largo plazo, se trata de fortalecer la resiliencia de las economías locales (Schippers et al, 2014; Verburg et al., 2015). Teniendo en consideración lo anterior, la custodia del territorio se puede convertir en una estrategia clave para incentivar cambios sobre los manejos de los sistemas agrarios en su conjunto desde una perspectiva socio-ecológica y de gobernanza territorial.

La custodia del territorio es una estrategia útil para fomentar la conservación de la naturaleza en terrenos privados, que está alcanzando cierto desarrollo y un importante prestigio en los últimos años. Lo que resulta innovador y marca la diferencia con otras estrategias de conservación, como es el caso de los contratos territoriales de explotación promovidos por las administraciones públicas, es que la iniciativa para formalizar los acuerdos surge por parte de la sociedad civil organizada. Para ello, la custodia del territorio busca establecer, a través de los acuerdos, compromisos de mantenimiento y mejora de los valores naturales, patrimoniales y paisajísticos entre los propietarios de la tierra y/o agricultores y las entidades de custodia. Las entidades de custodia funcionan como agentes dinamizadores para fomentar sistemas de gestión agraria integrales que puedan acercar objetivos de viabilidad económica con la preservación de los valores y la funcionalidad de los agroecosistemas (Yacamán et al., 2020b). Otro aspecto que diferencia el marco contractual de la custodia del territorio de los contratos territoriales de explotación es que los primeros se regulan mediante acuerdos voluntarios entre la entidad de custodia y la propiedad. Los acuerdos de custodia son flexibles y negociables (objeto, duración, compromisos entre ambas partes, régimen jurídico del contrato, etc.) entre las partes firmantes y se adaptan a las características de cada explotación. Esto permite que se adapten a la diversidad de los sistemas agrarios, integrando de forma sistémica las cualidades de los paisajes agrarios y contribuyendo al suministro de un conjunto de bienes públicos agroambientales (paisaje, patrimonio, variedades locales, razas autóctonas, suelo, agua, identidad y cultura) (De la Varga y Pons, 2018). Al contrario, los contratos territoriales de explotación son instrumentos de apoyo a las políticas de desarrollo rural, en general diseñadas con un enfoque top-down, que establecen un conjunto de compromisos a criterio de la Comunidad Autónoma, y en el cual el titular de la explotación agraria es compensado económicamente por las externalidades positivas generadas."

Para evitar la desconexión entre la producción de alimentos, la naturaleza y la sociedad, las entidades de custodia agraria ponen a disposición de las explotaciones agrarias asesoramiento técnico y soluciones para que los productores adopten prácticas concretas en torno la conservación de hábitats, para evitar la 
contaminación de los acuíferos y aguas superficiales, mejorar la fertilidad del suelo y favorecer la conservación de los elementos patrimoniales vinculados con los paisajes de la agricultura ${ }^{3}$. Las entidades de custodia realizan en primer lugar un diagnóstico sobre los valores del territorio para poder concretar los objetivos de conservación (tipos de razas autóctonas y su manejo, especies cultivadas y formas de cultivo, suelo y su manejo, sistemas de riego y aprovechamiento del recurso agua, etc.) en los acuerdos de prácticas agrarias sostenibles (Navarro, 2015). En este sentido, los contratos juegan un papel de vital importancia para mejorar la calidad del suministro alimentario y la conservación de bienes públicos agroambientales (Rodríguez et al., 2018).

Sin embargo, hay un creciente número de investigaciones que enfatizan la necesidad de fomentar los incentivos entre diversos agricultores para un suministro más eficiente a nivel de paisaje (Goldman et al., 2007; Stallman, 2011; Opdam et al., 2016; Yacamán et al., 2020c). Esto se debe a que el suministro de bienes públicos agroambientales y servicios de los ecosistemas dependen en gran medida de la estructura del paisaje: por ejemplo, la polinización, la calidad de las aguas superficiales y los acuíferos y el control de pestes, lo que exige una mayor coordinación entre múltiples gestores y propietarios de la tierra (Vialatte et al., 2019). Según lo anterior, resulta de mayor interés abordar contratos e incentivos agroambientales con enfoques colectivos arraigados al territorio, que mejoren la eficiencia del manejo de los usos del suelo en términos ecológicos y socioeconómicos adecuados a escala de paisaje (Yacamán et al., 2020c).

\section{ÁREA DE ESTUDIO, FUENTES Y METOdOLOGÍA}

\section{Introducción a los contextos territoriales de los estudios de caso exploratorios}

\section{El Valle del Jerte}

El Valle del Jerte, ubicado al norte de Extremadura, constituye un paisaje agrario singular y heterogéneo compuesto por mosaicos de cultivos, intercalado por prados, viñas y plantaciones de frutales (Figura 1). En el paisaje, puede observarse un largo proceso histórico derivado de la actividad agraria, que se ve plasmado en el aterrazamiento de las parcelas y en la construcción de un denso sistema de senderos y caminos rurales. La propiedad de la tierra ha estado generalmente sometida a un alto nivel de parcelación como resultado de las actividades realizadas por las explotaciones familiares. La agricultura familiar y de pequeña escala cumple una importante tarea de gestionar un rico patrimonio territorial y paisajístico, que ha favorecido el arraigo y la complicidad de la comunidad local. El cultivo tradicional está cargado de valores materiales e inmateriales que han servido para activar el carácter multifuncional de los paisajes agrarios, lo que ha favorecido la diversificación de la economía rural en las últimas décadas. El fuerte arraigo y sentido de pertenencia por parte de los productores, junto con los valores mencionados anteriormente, son aspectos que favorecen la articulación territorial, lo que sin duda se convierte en un atributo propio del carácter del paisaje y de la agricultura del Valle. Pero, al igual que muchas zonas rurales de España, es una región que se encuentra fuertemente amenazada por el envejecimiento y la despoblación.

Un elemento característico de la producción frutícola en esta zona es el importante asociacionismo agrario que, sin duda, ha servido como motor de desarrollo endógeno y transformación del sector productivo. Gracias al impulso de las cooperativas agrarias que tuvo lugar a partir de la década de los sesenta del siglo pasado, se introdujeron los productos del Jerte en los mercados de las grandes ciudades españolas, antes que los productos de otras regiones. Por este motivo, las picotas (cereza del Valle del Jerte) ganaron posición en el mercado, lo que favoreció la especialización productiva en la comarca (Caballero y Molina, 2019). En la década de los 90, se incrementaron las cooperativas agrarias especializadas en comercializar la cereza, un producto tradicional del Valle del Jerte. Este cooperativismo es un claro ejemplo de participación social, de base comunitaria y horizontal, en el que la población jerteña tomó la iniciativa de consolidar una gestión participativa en la búsqueda de un consenso que trazara los ejes estratégicos del desarrollo de la comarca (Leco et al., 2012).

Las características superiores de las picotas, el cuidado en cada una de las fases de la cadena de distribución, la recolección a mano de los frutos que están maduros, la fuerte vinculación entre la calidad y la localización montañosa de las explotaciones, junto con la consolidación del tejido asociativo, han permitido que los productores locales puedan obtener un buen precio que asegure la rentabilidad de muchas explotaciones (Figura 2). El resultado es que, en la actualidad, el Valle del Jerte concentra una de las 
producciones frutícolas más importantes de España. Según Caballero y Molina (2019), el salto de escala llegó con la creación de una cooperativa de segundo grado (la Agrupación de Cooperativas del Valle del Jerte) y la implementación de varias innovaciones tecnológicas y empresariales orientadas a fortalecer el monocultivo de la cereza. Se introdujo el frío en la postcosecha para alargar la vida útil del fruto, se hizo una reconversión varietal según las demandas del mercado y se creó la marca "Valle del Jerte" a través de la Denominación de Origen "Cereza del Jerte". Los cambios recientes en las explotaciones familiares asociados a la especialización productiva, según las entrevistas realizadas, han reducido la capacidad de los paisajes agrarios de proveer servicios de los ecosistemas de calidad. Como resultado, se roturaron los terrenos comunales, se redujo la ganadería y hubo un importante retroceso de otros cultivos tradicionales como el olivo, la viña y los castañares.

\section{El paisaje de montaña de Asturias}

Las condiciones orográficas y bioclimáticas de los paisajes montañosos de Asturias favorecieron los usos forestales y pecuarios. Los usos extensivos y tradicionales han creado paisajes singulares ganaderos de alta montaña con construcciones adaptadas al aprovechamiento de pastos en verano, en un espacio dominado por la propiedad colectiva de titularidad

FIGURA 1

PERSPECTIVA DEL VALLE DEL JERTE

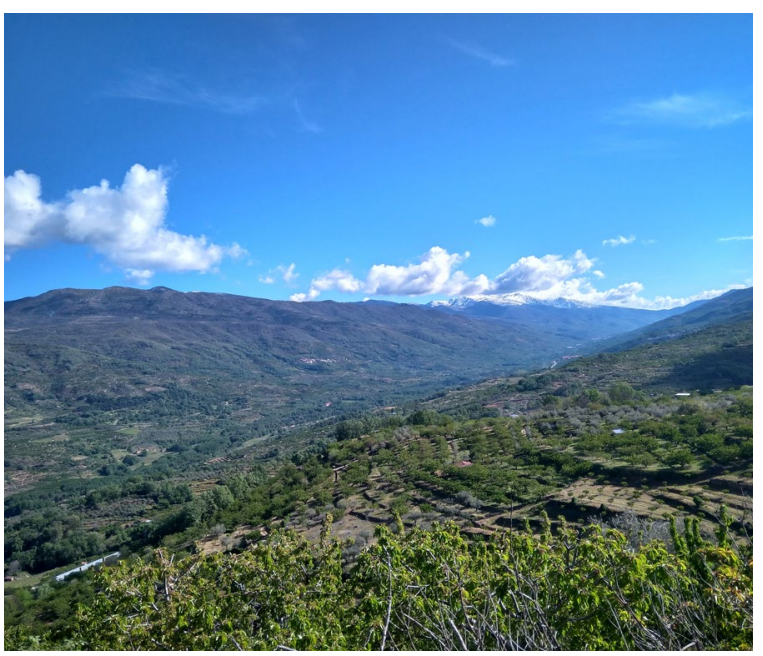

Copyright: Guillem Caballero. pública (Mata y Sanz, 2003). "Las producciones ganaderas extensivas del ganado vacuno autóctono y el sistema de trashumancia entre los pastos de altura y los valles, contribuyeron a la actual organización territorial, consistente en pequeños núcleos de población (aldeas y caseríos) distribuidos a lo largo de las rutas de trashumancia, desde los alojamientos invernales en caseríos y aldeas hasta las cabañas de las majadas más altas, utilizadas hoy para periodos temporales cortos pero múltiples a lo largo del verano" (MAPA, 2017, p. 13) (Figuras 3 y4).

En los paisajes de la montaña asturiana, el pastoreo extensivo ha desarrollado un importante papel en la economía de la sociedad rural. A su vez, la configuración de normas vecinales para la gestión del aprovechamiento en régimen colectivo de los pastos en cuestas y puertos de montaña ha sido esencial para la conservación de los valores paisajísticos de los mismos. En concreto, los vaqueros trashumantes tuvieron especial incidencia en las formas de organización y en la configuración del carácter de las cuencas vaqueras. Las cuencas vaqueras se definen como una variante de paisaje simbólico asturiano caracterizado por ceñirse a un ámbito territorial de un núcleo de población, en el que su actividad económica dominante es la ganadería bovina de carne, que se distribuye en pisos altitudinales que, en la mayoría de los casos, discurren por fondos de valle hasta el límite de las cumbres (Rodríguez y Martínez, 2009). Según las entrevistas realizadas, este sistema de gestión,

FIGURA 2

RECOLECCIÓN DE CEREZA POR MÉTODOS TRADICIONALES, A MANO Y FRUTO POR FRUTO EN EL VALLE DEL JERTE

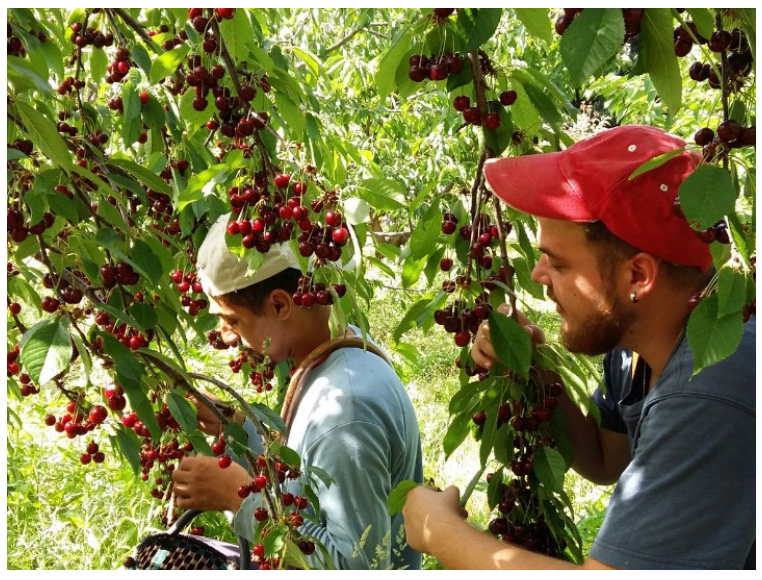

Copyright: Guillem Caballero. 
FIGURA 3

PAISAJE DE LA MONTAÑA ASTURIANA

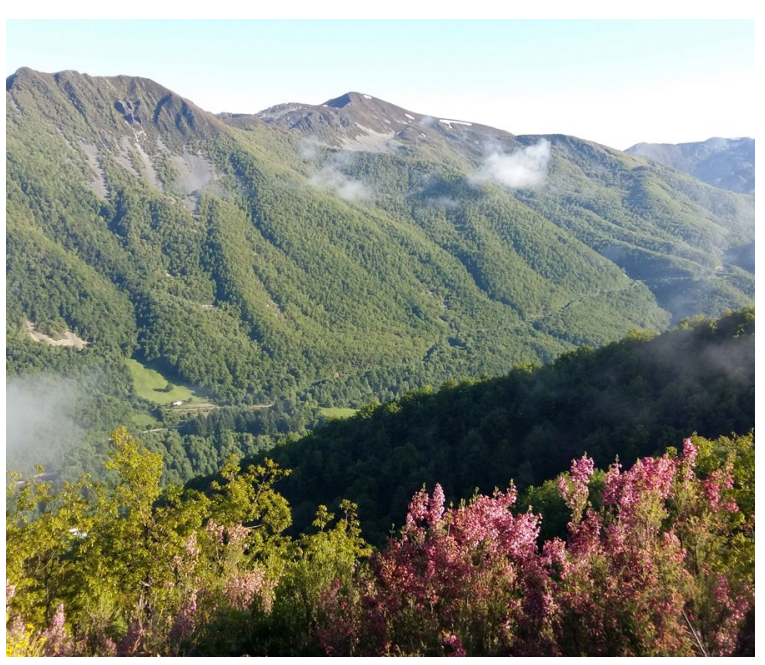

Copyright: Alberto Navarro.

característico de los pequeños ganaderos, hace que su viabilidad dependa mucho de la superficie comunal que puedan aprovechar. Pero, debido a la reducción de la actividad ganadera extensiva y a la reducción del pastoreo, se ha ido produciendo el avance de la matorralización de la montaña asturiana.

Con el descenso de la población rural que comienza a partir de la segunda mitad del siglo XX y los profundos cambios producidos sobre los modos de producción, especialmente por la sedentarización y la especialización de la ganadería, se crearon nuevas dinámicas en las áreas de montaña. Las especializaciones lechera y cárnica produjeron la práctica desaparición de ganados menores como las cabras y las ovejas que, antes de las recientes transformaciones, servían hacían de complemento productivo en régimen de semilibertad en el monte bajo (González, 2007). A pesar de la progresiva naturalización y del retroceso de la actividad agrícola y de la ganadería extensiva, siguen siendo paisajes altamente valorados por su gran belleza y esplendor.

\section{Fuentes de información y técnicas de análisis}

En primer lugar, se realizó una revisión bibliográfica sobre la innovación social, en la que se destacó el papel de las redes económicas alternativas y las entidades de la custodia del territorio para ayudar a movilizar el conocimiento y los procesos colectivos orientados hacia sistemas agroalimentarios sosteni-

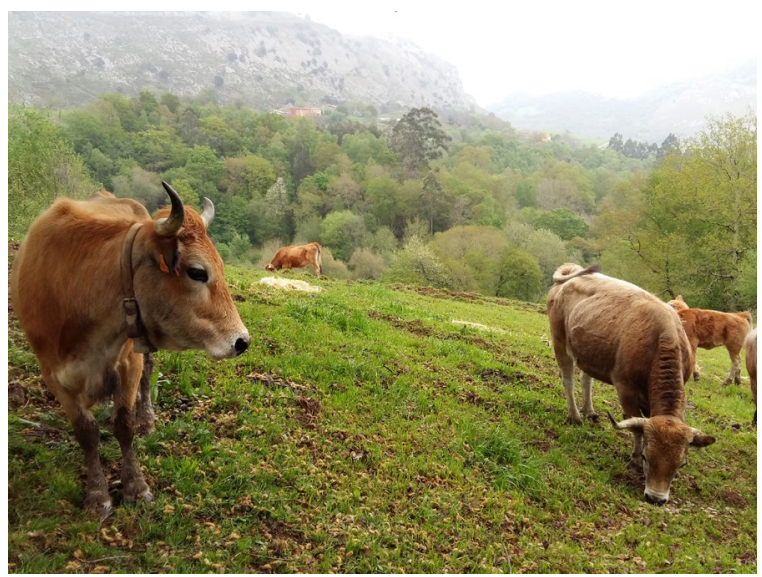

Copyright: Alberto Navarro.

bles. El objetivo de esta revisión fue elaborar un estado de la cuestión que sirviera de base para contribuir a mejorar la identificación de las prácticas colectivas que están jugando un papel clave a escala de paisaje. Adicionalmente, se realizó una revisión bibliográfica para conocer la evolución de los paisajes agrarios de cada estudio de caso exploratorio, con el objetivo de realizar una aproximación territorializada del sistema agroalimentario a escala local-regional y para comprender las dinámicas socioeconómicas en las que están insertas las iniciativas analizadas.

A continuación, se realizó un análisis descriptivo de dos iniciativas localizadas en ámbitos rurales en España. Los dos estudios de caso exploratorios seleccionados representan ejemplos de buenas prácticas para fortalecer la viabilidad de pequeños productores, crear nuevos productos de calidad y mejorar el suministro de bienes públicos agroambientales. Para la selección de los estudios de caso exploratorios, se buscaron iniciativas que agruparan pequeños productores y que llevaran a cabo acuerdos de custodia del territorio. Una vez realizada una primera selección de iniciativas en España, se seleccionaron dos que cumplieran con los siguientes criterios: trabajo en red, participación y horizontalidad en la toma de decisiones, acuerdos de custodia, estrategias de arraigo con el territorio y enfoque integrado del sistema agroalimentario.

La investigación adoptó un enfoque cualitativo. La principal fuente de información fueron las entrevistas en profundidad realizadas a las personas coordinado- 
ras de las redes, al ser las personas que tienen una visión más global de las iniciativas y un cuestionario entregado a cada iniciativa para ser rellenado por sus socios. Esta aproximación cualitativa no tiene por objeto recoger la diversidad de visiones aportada por distintos miembros dentro de cada iniciativa, sino seleccionar a una persona que actuase como informante clave en cada estudio de caso; aportando información en profundidad para caracterizar a las iniciativas. Las entrevistas tuvieron como objetivo conocer el origen de las iniciativas, los objetivos y su ámbito de actuación, su participación en el tejido social de sus comarcas y los principales factores de éxito y dificultades en el desarrollo de los procesos colectivos puestos en marcha. La descripción de las principales características de las iniciativas analizadas sirvió para elaborar la Tabla 1.

Las entrevistas se complementaron con un cuestionario para identificar las acciones concretas relacionadas con el enfoque cooperativo y los acuerdos de custodia del territorio, a partir de tres dimensiones del sistema agroalimentario que consideramos fundamentales: la económica, la territorial/ambiental y la cultural/política. La información obtenida de los cuestionarios sirvió para elaborar la Tabla 2, que sintetiza tanto las estrategias relativas a la innovación social aplicadas como los resultados que se obtienen cuando se aplica un enfoque colectivo y acuerdos de custodia. Los cuestionarios recogen información relativa a las estrategias asociadas al modelo cooperativo y a los acuerdos de custodia del territorio; los compromisos adquiridos por los miembros de la red; los servicios de los ecosistemas derivados de los acuerdos de custodia; y las sinergias generadas entre el enfoque cooperativo y las prácticas de custodia.

\section{RESULTADOS}

\section{Estudios de caso exploratorios de innovación social colectiva para avanzar hacia la ética de la producción y el consumo}

A continuación, se presentan los dos estudios de caso exploratorios seleccionados, localizados en el Valle del Jerte, en Extremadura, y en las zonas de montaña de Asturias. El foco del análisis se centra en el papel que tienen el enfoque cooperativo y los acuerdos de custodia para movilizar el conocimiento y los procesos colectivos orientados a fortalecer sistemas agroalimentarios multifuncionales y territorializados. Para sintetizar estos puntos, organizamos la información en una tabla comparativa de los dos estudios de caso (Tabla 1 ).

Tierra Sana, ubicada en el Valle del Jerte, es una asociación sin ánimo de lucro cuyo objetivo es difundir y compartir prácticas agroecológicas entre pequeños productores para favorecer un sistema agroalimentario sostenible y la promoción de una agricultura arraigada al territorio. La principal función de Tierra Sana es facilitar la cooperación entre sus asociados sobre diversos aspectos productivos, formativos y de comercialización. Se constituyó en los años 90, pero, tras un periodo de inactividad, en el año 2016, un grupo de jóvenes productores y productoras interesadas en la promoción de la soberanía alimentaria tomaron el relevo de la asociación para dinamizarla.

La tipología de los productores que componen la asociación corresponde a pequeñas explotaciones. En total, son 45 productores/as especializados en el cultivo ecológico de cereza (en un 75\%) y, en menor medida, en el cultivo de olivo, castaño e higos. Son explotaciones en su mayoría en régimen de propiedad, que no superan las 2-3 hectáreas. Catorce de las socias son mujeres ( $60 \%$ a dedicación completa, $30 \%$ a media jornada y $10 \%$ puntualmente), mientras que los hombres en su mayoría están a jornada completa (90\%). El cultivo en mosaico de algunas propiedades ha permitido que un pequeño porcentaje (aproximadamente el $10 \%$ ) complemente sus rentas con actividades de educación ambiental. La mayoría de sus asociados realiza una comercialización mixta: a través de otras cooperativas de la comarca a gran escala, mediante comercialización directa a grupos de consumo (Agrupación de Cooperativas del Valle del Jerte, Cooperativa del Campo en Navaconcejo, Cooperativa Agroecológica de Montaña y Grupo EcoJerte), en supermercados y mediante ventas por internet. Cuando la venta es mediante otros intermediaros se utiliza la marca "Jerte" de la Agrupación de Cooperativas del Valle del Jerte, que sirve como estrategia para identificar el origen del producto.

La asociación desarrolla una serie de iniciativas orientadas principalmente a fortalecer a la agricultura sostenible, multifuncional y territorializada. En especial, destaca la promoción de la custodia agraria orientada a mejorar la biodiversidad y la conservación del patrimonio natural en las explotaciones agrarias. Algunas de las medidas más destacadas sobre prácticas agrarias sostenibles, vinculadas a los acuerdos verbales de custodia agraria, son: promover la agricultura ecológica, la diversidad vegetal y la conservación de variedades tradicionales; conservar zonas 
TABLA 1.

PRINCIPALES ESTRATEGIAS DESARROLLADAS POR LOS ESTUDIOS DE CASO

\begin{tabular}{|c|c|c|}
\hline & Asociación Tierra Sana & Foro Asturias Sostenible \\
\hline $\begin{array}{l}\text { Estrategias } \\
\text { cooperativas } \\
\text { asociadas a la } \\
\text { producción, } \\
\text { distribución y } \\
\text { consumo. }\end{array}$ & $\begin{array}{l}\text { o Facilitar la compra de insumos de forma colectiva } \\
\text { o Incentivar la comercialización conjunta } \\
\text { o Mejorar el conocimiento horizontal a través del } \\
\text { intercambio de experiencias "campesino a campesino“ } \\
\text { o Fomentar la alimentación ecológica en toda la cadena: } \\
\text { producción, elaboración, comercialización y venta } \\
\text { o Crear dinámicas de apoyo mutuo para el trabajo de } \\
\text { campo } \\
\text { o Estimular la incorporación de personas jóvenes en la } \\
\text { agricultura y favorecer el papel y visión de la mujer } \\
\text { o Mejorar la cualificación técnica (realización de jornadas y } \\
\text { seminarios sobre sostenibilidad transversal) } \\
\text { o Innovar aplicando técnicas agroecológicas } \\
\text { o Generar una marca territorializada }\end{array}$ & $\begin{array}{l}\text { o Favorecer una logística de repartos común } \\
\text { o Optimizar los repartos de trabajo entre } \\
\text { comercialización, venta y promoción } \\
\text { o Fomentar el consumo interno de los productos } \\
\text { de los asociados } \\
\text { o Fomentar mecanismos asamblearios de decisión } \\
\text { o Mejorar la información a consumidores } \\
\text { o Crear instalaciones comunes de almacenaje de } \\
\text { producto fresco y congelado } \\
\text { o Generar trabajo digno a quienes realizan alguna } \\
\text { labor para la red } \\
\text { o Crear una imagen común de todos los } \\
\text { miembros de la red } \\
\text { o Generar una marca territorializada }\end{array}$ \\
\hline Networking & o Redes Alimentarias Alternativas & $\begin{array}{l}\text { o Plataforma por la Ganadería Extensiva y el } \\
\text { Pastoralismo } \\
\text { o Iniciativa comunales (ICCA Consortium). } \\
\text { o Red Transcantábrica de Custodia del Territorio }\end{array}$ \\
\hline $\begin{array}{l}\text { Medidas sobre } \\
\text { prácticas agrarias } \\
\text { sostenibles } \\
\text { vinculadas a los } \\
\text { acuerdos de } \\
\text { custodia agraria }\end{array}$ & $\begin{array}{l}\text { o Promover la diversidad vegetal y la conservación de } \\
\text { variedades tradicionales } \\
\text { o Promover la agricultura ecológica } \\
\text { o Mejorar los niveles de fertilidad física, biológica y química } \\
\text { del suelo } \\
\text { o Conservar zonas húmedas naturales y puntos de agua } \\
\text { para la fauna silvestre } \\
\text { o Conservar el patrimonio histórico } \\
\text { o Gestionar plásticos agrícolas } \\
\text { o Conservar árboles, setos vegetales y bosquetes y la } \\
\text { plantación de lindes, compatibles con actividad agraria } \\
\text { o Mantener cubiertas vegetales a lo largo de todo el año } \\
\text { o Generar espacios de biodiversidad vegetal en las fincas } \\
\text { (en perímetros e interior) para albergar durante el mayor } \\
\text { periodo del año a insectos y aves auxiliares } \\
\text { o Mantener zonas y/ rodales en los que se conserva la } \\
\text { vegetación espontánea } \\
\text { o Fomentar prácticas agrarias tradicionales (ej. barbechos y } \\
\text { rotación con leguminosas) } \\
\text { o Fomentar el empleo de medidas alelopáticas y de control } \\
\text { biológico de plagas agrícolas } \\
\text { o Integrar a la mujer en la actividad productiva y de gestión }\end{array}$ & $\begin{array}{l}\text { o Fomentar la producción ecológica certificada y } \\
\text { buenas prácticas agroecológicas } \\
\text { o Mantener sebes (orlas), arboledas, muros de } \\
\text { piedra seca, cabañas y otras construcciones } \\
\text { tradicionales como cortines (espacios cerrados } \\
\text { de piedra para proteger colmenas del oso) } \\
\text { o Evitar insumos de piensos transgénicos } \\
\text { o Mantener razas en peligro de extinción (vacas } \\
\text { casinas, ovejas xaldas, cerdos asturceltas y } \\
\text { caballos asturcones) } \\
\text { o Mantenimiento de la biodiversidad silvestre } \\
\text { emblemática (ej. buitre leonado, } \\
\text { quebrantahuesos, alimoche, oso, lobo, } \\
\text { urogallo) } \\
\text { o Generar micro hábitats para la fauna y } \\
\text { pequeñas manchas boscosas. } \\
\text { o Promover el pastoreo en montes comunales } \\
\text { o Conservar cierres tradicionales en piedra y } \\
\text { vegetales } \\
\text { o Proteger árboles singulares } \\
\text { o Conservación de semillas locales de alubias y } \\
\text { maíz para autoconsumo }\end{array}$ \\
\hline
\end{tabular}

Fuente: Elaboración propia

húmedas para la fauna silvestre; proteger el patrimonio ligado a la agricultura; conservar bosquetes y setos vegetales; y mantener cubiertas vegetales a lo largo del año. Gracias a la aplicación de estas medidas en diversas fincas, se está logrando incidir en la calidad del suministro de los servicios de los ecosistemas a escala de paisaje (Tabla 2). También se organizan formaciones orientadas a mejorar la innovación en el manejo de las fincas mediante la aplicación de técnicas agroecológicas. Para ello, la asociación realiza de forma continua cursos para promover el intercambio de experiencias entre los socios y otros agentes, según las demandas y necesidades de la comarca. Entre sus principales señas de identidad está la aplicación de metodologías que integran el conocimiento técnico y especializado con los saberes "de campesino a campesino". Además, coordinan mercados y eventos para mejorar la visibilidad de los pequeños productores. A lo largo de los últimos años, las actividades se han vertebrado a través de dos espacios: un espacio informal creado a partir de encuentros festivos y lúdicos, para fomentar la cohesión social y el sentido de pertenencia, y otro más formal relativo a reuniones y asambleas para tratar temas relacionados con la producción, distribución y transformación de los productos.

Las asambleas y la horizontalidad en la toma de decisiones, la co-construcción de conocimiento resul- 
TABLA 2

OPORTUNIDADES DE APLICAR EL ENFOQUE COLECTIVO Y LA CUSTODIA DEL TERRITORIO Y LOS FACTORES LIMITANTES

\begin{tabular}{|c|c|c|}
\hline & Asociación Tierra Sana & Foro Asturias Sostenible \\
\hline $\begin{array}{l}\text { Servicios de los } \\
\text { ecosistemas vinculados } \\
\text { con los acuerdos de } \\
\text { buenas prácticas } \\
\text { agrarias }\end{array}$ & $\begin{array}{l}\text { o Mantenimiento del hábitat para especies autóctonas } \\
\text { o Protección de los recursos hídricos } \\
\text { o Complementar la producción con la educación } \\
\text { ambiental } \\
\text { o Conservación de variedades tradicionales (ej. olivo, } \\
\text { variedad típica de picota del Valle del Jerte) } \\
\text { o Mantenimiento de la fertilidad del suelo a través de } \\
\text { manejos agroecológicos }\end{array}$ & $\begin{array}{l}\text { o Conservación de semillas locales } \\
\text { o Conservación de elementos identitarios de los } \\
\text { ecosistemas silvopastoriles } \\
\text { o Mantenimiento de la biodiversidad silvestre } \\
\text { emblemática } \\
\text { o Protección de razas ganaderas autóctonas (acervo } \\
\text { genético) }\end{array}$ \\
\hline $\begin{array}{l}\text { Resultados generados } \\
\text { de aplicar el enfoque } \\
\text { cooperativo y los } \\
\text { acuerdos de custodia }\end{array}$ & $\begin{array}{l}\text { o Co-construcción de conocimiento: nuevos manejos } \\
\text { del agroecosistema desde un enfoque agroecológico } \\
\text { o Mayor sentimiento de pertenencia y espíritu crítico } \\
\text { o Nuevos contactos } \\
\text { o Mejora de la competitividad de la producción } \\
\text { frutícola } \\
\text { o Valor añadido y visibilidad del producto local } \\
\text { o Mayor empoderamiento de los productores locales } \\
\text { o Identificación de soluciones comunes e individuales } \\
\text { o Mayor visibilidad en el mercado }\end{array}$ & $\begin{array}{l}\text { o Mayor solidez en el tejido asociativo } \\
\text { o Mayor empoderamiento de los productores } \\
\text { locales } \\
\text { o Incremento del valor añadido de los productos } \\
\text { locales } \\
\text { o Revalorización de las razas locales } \\
\text { o Diversificación económica } \\
\text { o Visión común del territorio } \\
\text { o Nuevas oportunidades de mercado } \\
\text { o Nuevos contactos } \\
\text { o Puesta en valor de los bienes comunes } \\
\text { o Conservación de la agrobiodiversidad } \\
\text { o Mejorar el desarrollo rural integrado }\end{array}$ \\
\hline $\begin{array}{l}\text { Factores que limitan } \\
\text { aprendizajes y } \\
\text { procesos colectivos } \\
\text { para producir } \\
\text { soluciones más } \\
\text { integrales }\end{array}$ & $\begin{array}{l}\text { o Ir más allá de la dimensión económica del } \\
\text { cooperativismo y trabajar las dimensiones eco- } \\
\text { sociales con la comunidad } \\
\text { o Mantener un cooperativismo real (aplicable también } \\
\text { a fincas de mayores dimensiones) } \\
\text { o Heterogeneidad en el tamaño de las fincas } \\
\text { o Distanciamiento físico de algunas explotaciones. } \\
\text { o Escasa rentabilidad económica de algunas } \\
\text { explotaciones } \\
\text { o Dificultad de cooperar cuando la diversidad de } \\
\text { perfiles es alta y la proximidad espacial es reducida }\end{array}$ & $\begin{array}{l}\text { o Escasa de participación por parte de todos los } \\
\text { miembros } \\
\text { o Dificultades de coordinación por la falta de } \\
\text { proximidad espacial } \\
\text { o Escasa rentabilidad económica de algunas } \\
\text { explotaciones } \\
\text { o Escasa estabilidad en el compromiso de los } \\
\text { consumidores } \\
\text { o Escasos recursos y tiempo para aportar en las } \\
\text { iniciativas de colaboración } \\
\text { o Falta de experiencia y referencias en proyectos } \\
\text { similares }\end{array}$ \\
\hline
\end{tabular}

Fuente: Elaboración propia

tante de las formaciones orientadas a la transformación multifuncional y territorializada de los sistemas agrarios locales y la identificación de soluciones comunes e individuales sobre la comercialización y la visibilidad en el mercado, son entendidos como ejemplos de innovación social frente a otras cooperativas agrarias de la comarca (Tabla 2). Las iniciativas de carácter comunitario para fortalecer el sentido de pertenencia, el espíritu crítico y el empoderamiento de los pequeños productores son, según las entrevistas, los elementos fundamentales para impulsar el proceso de transición agroecológica. Con respecto a los problemas identificados en las entrevistas, que limitan el aprendizaje colectivo y la escalabilidad de las prácticas agroalimentarias sostenibles entre los miembros de la red y otros productores locales, se señalan la heterogeneidad en el tamaño de las fincas, las limitaciones derivadas del distanciamiento físico de algunas explotaciones y las diferencias en aspectos formativos y políticos de sus miembros, así como la dificultad percibida para poder incorporar en la asociación explotaciones agrarias con mayores dimensiones.

La segunda experiencia analizada es el Foro "Asturias Sostenible". Esta red está orientada a fomentar el desarrollo de una agricultura y ganadería extensivas y sostenibles desde una triple perspectiva: social, ambiental y económica. Uno de sus principales objetivos es garantizar la viabilidad de las pequeñas granjas familiares asturianas para apoyar el mantenimiento de un tejido rural cohesionado y digno. La tipología de los productores que componen el Foro "Asturias Sostenible" son también pequeñas explotaciones: está compuesta por 22 productores rurales ( 5 mujeres y 17 hombres) que se han agrupado para desarrollar funciones de comercialización conjunta. Las explotaciones que conforman la red crían ganado tradicional y extensivo y trashumante de montaña 
con pastos propios, arrendados y en régimen comunal. Sus productos tienen un valor añadido que se identifica a través de la marca comercial propia "Asturias Sostenible" y por la Indicación Geográfica Protegida "Ternera Asturiana", que comprende la totalidad del Principado de Asturias y asegura que el manejo y la alimentación de los animales conserven los métodos tradicionales basadas en el aprovechamiento de pastos naturales.

Son explotaciones mayoritariamente trabajadas en régimen familiar y dedicadas a la ganadería para producción de carne (vacuna, ovina, caprina), leche y derivados (yogures, quesos y cremas), miel y, en menor grado, explotaciones hortofrutícolas que venden producto fresco y procesado en conservas. Siete explotaciones ganaderas tienen certificación ecológica: ocupan una superficie entre las 2 hectáreas (cultivo hortícola) y las cerca de 50 hectáreas (ganadería extensiva). Las tierras del terrazgo son comúnmente de propiedad y arrendadas a vecinos o familiares no residentes (unas 240 hectáreas manejadas por los socios productores). Las explotaciones ganaderas de carne son siempre extensivas y disponen de terreno comunal (200 hectáreas aproximadamente de comunales manejadas por los socios). Algunas queserías realizan además actividades de agroturismo y educación ambiental para complementar sus rentas. La comercialización conjunta de los socios se realiza a través de diferentes canales, especialmente mediante distribución directa: grupos de consumo (12 grupos con 180 socios consumidores individuales o familiares), cuatro restaurantes y ventas por internet. Para mejorar la confianza y comunicación directa entre sus consumidores, se realizan visitas a pie de finca.

La importante participación en otras redes, como la "Plataforma por la Ganadería Extensiva y el Pastoralismo" y la "Iniciativa Comunales" (ICCA Consortium), ha sido considerada esencial para consolidar su apuesta por un sistema agroalimentario más territorializado, capaz de hacer frente a los desafíos que tiene el actual modelo de producción y distribución industrial y el consumo deslocalizado. En su apuesta por fomentar la custodia del territorio en Asturias, además de participar en la "Red Transcantábrica de Custodia del Territorio", llevan fomentando desde el año 2012 acuerdos entre los socios con el objetivo de mejorar el suministro de bienes públicos agroambientales (Tabla 1).

Algunas de las medidas más destacadas sobre prácticas agroecológicas vinculadas a los acuerdos de custodia agraria son: fomentar la producción ecoló- gica; conservar bosquetes, muros de piedra seca y construcciones tradicionales; mantener razas en peligro de extinción (vacas casinas, ovejas xaldas, cerdos asturceltas y caballos asturcones); promover el pastoreo en montes comunales; y conservar cierres tradicionales en piedra y vegetales. Estas medidas realizadas por varias explotaciones han generado una mejora a nivel de paisaje en los servicios de los ecosistemas: conservación de semillas locales, conservación de elementos identitarios de los ecosistemas silvopastoriles, mantenimiento de la biodiversidad silvestre emblemática y protección del acervo genético de razas ganaderas autóctonas (Tabla 2).

El enfoque de planificación colaborativa, bajo objetivos comunes orientados a fortalecer la comercialización colectiva a través de canales cortos, y una apuesta decidida por apoyar formas de vida tradicionales son elementos esenciales para asegurar la innovación social sostenible en el medio rural (Tabla 2). Según las entrevistas realizadas, los beneficios percibidos por los socios de pertenecer al Foro "Asturias Sostenible" son múltiples, entre los que destacan los siguientes: la creación de nuevos nichos de mercado en torno al consumo sostenible, el aumento del valor añadido de los productos, así como aspectos económicos vinculados con un mayor rendimiento económico y el reconocimiento social que aporta un valor agregado al producto por su labor de mantenimiento y gestión del paisaje. Se observa además que, cuando se combina el enfoque cooperativo con las estrategias de custodia del territorio, se tiende a mejorar la calidad de los productos, se empodera el tejido asociativo $y$, en definitiva, se puede llegar a fortalecer el desarrollo rural integrado (Tabla 2). Sin embargo, los entrevistados resaltan que quedan muchos retos por afrontar para consolidar los procesos colectivos puestos en marcha. Entre ellos, destacan los siguientes: incrementar la participación activa por parte de todos los miembros, reducir los problemas de coordinación entre los socios por la falta de proximidad espacial, mejorar la rentabilidad económica de algunas explotaciones (lo que debilita la capacidad para integrar nuevas innovaciones) e incrementar el compromiso estable por parte de los consumidores a lo largo del tiempo.

\section{Discusıón}

De acuerdo con la hipótesis que ha guiado la investigación, existen ciertos procesos desarrollados por las redes analizadas que podrían desempeñar un 
papel destacado en la movilización y la estabilización de las innovaciones sociales sostenibles. Por ejemplo, los acuerdos voluntarios alcanzados al interior de las redes parecen desarrollar un papel esencial para consolidar aspectos organizativos orientados a fomentar la creatividad y el aprendizaje, así como para fomentar un cambio de procedimientos sobre los métodos de producción y comercialización, lo que puede identificarse como innovación social frente al comportamiento observado en otras cooperativas agrarias tradicionales. Al analizar los estudios de caso, podemos observar que la innovación social, entendida como nuevas formas de trabajo cooperativo arraigadas al territorio, puede llegar a generar nuevas soluciones para la cadena alimentaria, lo que resulta esencial para empoderar a los pequeños productores: marcas territorializadas; nuevos aprendizajes y habilidades colectivas que surgen del propio colectivo; imagen común, recursos, estrategias y objetivos compartidos; participación en la toma de decisiones; producción de alimentos saludables y de calidad; y fortalecimiento del desarrollo local.

Históricamente, los servicios de extensión agraria desempeñaron un papel fundamental en la acumulación y transferencia de conocimientos técnicos; en la actualidad, este servicio ha sido principalmente privatizado y se ha centrado en difundir prácticas industriales (Laurent et al., 2006). Ante la ausencia de este servicio público, las formas cooperativas arraigadas a los conocimientos rurales tradicionales son esenciales para evitar la intensificación y especialización productiva y la pérdida de prácticas culturales. En este sentido, al analizar los resultados según la opinión de los actores entrevistados, las redes con enfoque agroecológico suelen tener una visión más dinámica para mejorar el acceso a los conocimientos técnicos entre los productores a pequeña escala (Kroma, 2006; García-Llorente et al., 2019). Como señala Neumeier (2012), el potencial de las innovaciones sociales está fuertemente arraigado en la existencia de redes sociales y de capital social disponible en los territorios. Según lo anterior, podemos observar cómo las redes arraigadas al territorio pueden llegar a constituir agentes valiosos, por su capacidad catalizadora para favorecer un proceso de coproducción de conocimiento necesario para lograr el cambio de actitud sobre una nueva ética de producción, distribución y consumo.

La custodia del territorio tiene potencial para llegar a ser considerada como una herramienta idónea para movilizar el potencial endógeno y para revalorizar los elementos identitarios regionales mediante el empoderamiento de la sociedad civil. Todos estos aspectos han sido considerados fundamentales para fortalecer sistemas agroalimentarios territorializados y multifuncionales. Específicamente, los acuerdos de custodia son impulsores de una innovación social sostenible, como afirma Bock (2016), dado que son una manera de incentivar el desarrollo territorial integrado, reemplazando el papel gubernamental mediante la movilización de acuerdos voluntarios y estructuras de autogobierno de carácter comunitario, que toman la iniciativa y asumen el liderazgo de su revitalización.

Asimismo, al analizar los resultados, se observa que las entidades de custodia son esenciales para reconciliar la agricultura con la conservación de los servicios de los ecosistemas, mediante la trasferencia de conocimiento sobre nuevas técnicas y manejos a escala de finca compatibles con la conservación de la biodiversidad. En este sentido, podemos concluir que el trabajo en red de actores con diferentes perfiles (entidades de custodia, productoras, técnicas, etc.), con diferentes intereses y experiencias previas, puede tener mayor capacidad de trasladar el conocimiento en acción que las redes endogámicas (por ejemplo, compuestas exclusivamente por productores o por entidades conservacionistas). Como indican MeinzenDick et al. (2009), los grupos reducidos que comparten los mismos valores y objetivos, la existencia de motivación, la confianza y las habilidades para la gestión colectiva y el conocimiento, son aspectos claves para fortalecer la acción colectiva.

Los dos estudios de caso son buenos ejemplos de la importancia de dinamizar nuevos procesos y modelos de organización social, como son los promovidos por la agroecología y por la custodia del territorio, dado que se pueden adecuar mejor a los intereses y las necesidades locales, garantizando simultáneamente un suministro diversificado de servicios de los ecosistemas (Duru et al., 2015; Verburg et al., 2015; Dendoncker et al., 2018; García-Llorente et al., 2019). El uso de enfoques transdiciplinares, que integran producción de conocimiento y aprendizajes colectivos para mejorar la planificación integrada de los sistemas agrarios, puede ser útil tanto para mejorar la identificación de problemas y desafíos locales como para producir soluciones socio-ecológicas más robustas y duraderas (Angelstam et al., 2013). Este enfoque puede ser una oportunidad para identificar y aumentar el valor añadido de los productos territorializados, dada la diversidad de los sistemas agrarios españoles, 
lo que les proporciona una ventaja competitiva frente a alimentos producidos en masa que no incorporan los valores tangibles e intangibles de los agroecosistemas y de sus comunidades. Esto se consigue cuando se crean acuerdos colectivos que vinculan alimentos tradicionales con los valores del territorio: por ejemplo, a través estrategias como la Denominación de Origen Protegida o la Indicación Geográfica Protegida o, de forma alternativa, mediante iniciativas participativas con enfoques botton-up. En este sentido, la sinergia entre territorio y saber campesino otorga a la agricultura un valor estratégico como práctica que reconoce la singularidad y la calidad asociada a un paisaje próximo y con historia (Yacamán et al., 2020b). En definitiva, esta nueva perspectiva, eminentemente territorial, constituye la base para la formulación de planteamientos innovadores en torno al desarrollo de estrategias entre diversos agentes locales vinculados a la alimentación, con el fin de avanzar hacia la transición agroecológica del sistema agroalimentario.

A pesar de todas las sinergias obtenidas cuando se aplican enfoques colectivos en los acuerdos de custodia, también existen ciertas barreras que limitan los procesos de innovación social, como son la escasa confianza en los procesos participativos, la dificultad de fomentar dinámicas cooperativas entre agentes con perfiles heterogéneos, el limitado compromiso por parte del consumidor con respecto a los productos diferenciados, la insuficiente capacidad para movilizar a las comunidades locales para rediseñar y mejorar la organización territorial y las escasas experiencias de referencia sobre las cuales inspirarse. A ellos se pueden sumar otras limitaciones señaladas por la literatura, como el efecto free-rider o el escaso apoyo institucional (OECD, 2013; García-Llorente et al., 2019).

En definitiva, los estudios de caso exploratorios señalan que a través de la cooperación se puede obtener un beneficio mayor que no podría lograrse mediante el esfuerzo individual de pequeños productores con capacidad económica limitada. Esto es también especialmente pertinente para transformar el sistema agroalimentario y para mejorar el suministro de los servicios de los ecosistemas a escala de paisaje (por ejemplo, el control de plagas, los hábitats para especies, la conectividad ecológica o la conservación de variedades y razas locales). En este sentido, es pertinente reconocer la necesidad de redefinir la escala de los procesos, de manera que las explotaciones, primero, realicen los manejos de forma coordinada a escala de paisaje en lugar de como unidades independientes $y$, en segundo lugar, que incorporen los diversos servicios de los ecosistemas en sus prácticas agrarias con una base agroecológica (Goldman et al., 2007; Yacamán et al., 2020c). Finalmente, los dos estudios de caso exploratorios analizados muestran la importancia de crear sinergias a diferentes escalas (finca, agroecosistema, región y nacional) para avanzar en los procesos de transición agroecológica.

\section{CONCLUSIONES}

Los cambios más importantes para favorecer la transición del sistema agroalimentario resultan de las interacciones multinivel a diferentes escalas (finca, paisaje, comunidad y mercado), entre diferentes agentes y mediante el reconocimiento de la contribución de los sistemas agrarios rurales en la seguridad alimentaria. A su vez, el enfoque cooperativo y la custodia del territorio se presentan como dos oportunidades con capacidad para favorecer las innovaciones sostenibles orientadas a potenciar el desarrollo rural integrado, el empoderamiento de los pequeños productores, la mejora de su visibilidad y el apoyo a una agricultura territorializada y multifuncional. Cuando las estrategias cooperativas se combinan con la custodia del territorio, se pueden llegar a impulsar cambios más radicales y duraderos: por ejemplo, sirven para reducir la continuada pérdida de cuota de mercado, incentivar la producción de alimentos saludables y conservar la biodiversidad y los paisajes agrarios tradicionales. A su vez, el valor añadido asociado a la protección del medio ambiente y la trazabilidad del origen de los alimentos, son nuevas oportunidades de mercado que los pequeños productores pueden aprovechar.

Cuando se logran crear sinergias entre el enfoque cooperativo y la custodia del territorio, bajo el marco de la agroecología, se contribuye a mejorar el enfoque sistémico del sistema agroalimentario desde el origen, es decir incidiendo en la base del metabolismo de los sistemas de producción de alimentos. En concreto, la custodia agraria aprovecha los recursos endógenos y las prácticas culturales asociadas a la gestión del paisaje, mientras que el enfoque cooperativo logra transformar estructuralmente la gobernanza del sistema agroalimentario dominante al equilibrar las fuerzas de poder entre los agentes de la cadena alimentaria. La sinergia de estas dos estrategias ayuda a redefinir el modelo de producción y consumo desde una perspectiva territorializada. Ade- 
más, bajo el marco de la agroecología, las explotaciones agrarias introducen tanto innovaciones técnicas como organizativas, necesarias para asegurar un uso más eficiente de los recursos naturales en el sistema agrario a escala local-regional. En este sentido, los procesos construidos bottom-up, que integran las especificidades del territorio con la generación de bienes públicos agroambientales en la producción agraria, pueden generar soluciones transformadoras para contrarrestar las presiones producidas por la intensificación, la especialización y la deslocalización alimentaria.

Analizando la importancia de la escala en los procesos de innovación social orientados a la transformación del sistema agroalimentario globalizado, vemos que la escala local-regional favorece alianzas más estructurales como resultado de la interacción social y la proximidad espacial. Surgen nuevas soluciones a problemas locales, identificadas por un grupo de personas. Aunque la escala local-regional permite cambios más micro, los cambios que genera en los patrones de producción y consumo pueden ser más renovadores y, podríamos decir, más radicales, pues se basan en fomentar cambios en el sistema de valores de la comunidad, sobre todo en aquellas cuestiones que tienen que ver con la percepción sobre la "calidad del producto". En este sentido, la confianza se convierte en un pilar fundamental, junto con el

\section{NOTAS}

1 La intensificación a escala de finca es entendida en este artículo como el incremento en los aportes externos (fertilizantes y pesticidas de origen químicos) usados por hectárea de suelo, con el objetivo de incrementar el nivel de producción por unidad de cultivo y unidad de trabajo.

2 La especialización a escala de finca ocurre cuando un único tipo de cultivo domina la renta agraria. También se asocia con el aumento del uso de insumos químicos (por unidad de área), lo que puede causar una variedad de problemas ambienta- sentido de pertenencia y el arraigo al territorio, para recomponer las alianzas a escala local-regional del sistema agroalimentario. Finalmente, podemos concluir de nuestro análisis que, si bien las estrategias de innovación social que se tejen son contexto-dependientes y específicas de cada territorio, su éxito (o fracaso) depende fundamentalmente de la existencia de redes sociales y de su capacidad para revalorizar los recursos endógenos de los territorios.

\section{RECONOCIMIENTOS}

Agradecemos a las dos entidades que han dedicado su tiempo a realizar la entrevista y por las fotografías cedidas para ilustrar los estudios de caso. Este estudio recibió financiación del programa de investigación e innovación Horizonte 2020 de la Unión Europea, en el marco del convenio de subvención $\mathrm{N} \circ 81819$, por el proyecto titulado: Codiseño de nuevos modelos de contrato para medidas innovadoras agroambientales y climáticas y para la valorización de bienes públicos ambientales y del proyecto SAVIA-Sembrando Alternativas de Innovación Agroecológica, financiado por las ayudas de la convocatoria 2019 a proyectos de I+D para jóvenes investigadores de la Universidad Autónoma de Madrid (ref: SI1/PJI/2019-00444).

les, cuando los restos de los aportes suministrados a los cultivos no pueden absorberse y pueden filtrarse en el agua, el suelo y el aire (EUROSTAT, 2019).

3 Para más información sobre acuerdos de prácticas agrarias sostenibles ver: Grup Balear d'Ornitologia i Defensa de la Naturalesa (GOB) (2008). Custodia del territorio. El acuerdo de prácticas agrarias sostenibles en Menorca. GOB Menorca. Recuperado de https://www.gobmenorca.com/sites/default/ files/quadern_castella.pdf 


\section{REFERENCIAS BIBLIOGRÁFICAS}

Angelstam, P., Grodzynskyi, M., Andersson, K. et al. (2013). Measurement, Collaborative Learning and Research for Sustainable Use of Ecosystem Services: Landscape Concepts and Europe as Laboratory. AMBIO 42, 129-145. doi: https://doi.org/ $10.1007 / \mathrm{s} 13280-012-0368-0$

Anderson, C. R., Maughan, C., y Pimbert, M. P. (2019). Transformative agroecology learning in Europe: building consciousness, skills and collective capacity for food sovereignty. Agriculture and Human Values, 36, 531-547. doi: https://doi.org/10.1007/ s10460-018-9894-0

Altieiri, M. A. (2009). Agroecology, small farms, and food sovereignty. Monthly Review, 61(3), 102111. doi: https://doi.org/10.14452/MR-061-03 -2009-07_8

Bock, B (2016). Rural marginalisation and the role of social innovation: a turn towards nexogenous development and rural reconnection. Sociologia Ruralis, 56(4), 552-573. doi: https://doi.org/ $10.1111 /$ soru.12119

Caballero, G., y Molina, K. (2019). ¿Hacia dónde camina el Valle del Jerte? Soberanía Alimentaria, Biodiversidad y Culturas, 36, 44-49. Recuperado de https://soberaniaalimentaria.info/images/ descargas/sabc_36.pdf

Caravaca Barroso, I. (2017). Globalización neoliberal y crisis en los espacios ganadores y emergentes. Ciudad y Territorio: Estudios Territoriales, 49(194), 613-628. Recuperado de Revista Ciudad y Territorio, Estudios Territoriales. C y TET no 194 ; Vol. XLIX. Cuarta época, invierno (fomento.gob.es)

Cumming, G.S., Buerkert, A., Hoffmann, E.M. et al., (2014). Implications of agricultural transitions and urbanization for ecosystem services. Nature, 515(7525), 50-57. doi: https://doi.org/10.1038/ nature13945

Davies A, Simon J, Patrick R y Norman W. (2012). Mapping citizen engagement in the process of social innovation. A deliverable of the project: 'The theoretical, empirical and policy foundations for building social innovation in Europe'. (TEPSIE) European Commission - 7th Framework Programme, European Commission, DG Research, Brussels. Recuperado de Mapping-citizen-engagement-in-the-process-of-social-innovation.pdf (youngfoundation.org)
De la Varga, A., y Pons, J. (2018). Innovative legal tools applied in land stewardship for the conservation of ecosystem services in Catalonia. Ecosystem Services, 29, 395-403. doi: https://doi.org/ 10.1016/j.ecoser.2017.08.010

Dendoncker, N., Boeraeve, F., Crouzat, E., Dufrêne, M., König, A. y Barnaud, C. (2018). How can integrated valuation of ecosystem services help understanding and steering agroecological transitions? Ecology and Society, 23(1), 12. doi: https://doi.org/10.5751/ES-09843-230112

Di lavoco, F., Moruzo, R., Rossignoli, C., y Scarpellini, P. (2014). Transition management and social innovation in rural areas: lessons from social farming. Journal of Agricultural Education and Extension, 20(3), 327-347. doi: https://doi.org/10.1 080/1389224X.2014.887761

Duru, M., Therond, O., y Fares, M. (2015) Designing agroecological transitions: A review. Agronomy for Sustainable Development, 35, 1237-1257. doi: https://doi.org/10.1007/s13593-015-0318-x

EME (Evaluación de los Ecosistemas del Milenio de España) (2011). La Evaluación de los ecosistemas del Milenio de España. Síntesis de resultados Madrid: Fundación Biodiversidad. Ministerio de Medio Ambiente y Medio Rural y Marino. Recuperado de Informe Síntesis de EME (ecomilenio.es)

EUROSTAT (2019). Agri-environmental indicator - fact sheet of the European Union (EU) agri-environmental indicator specialisation. Recuperado de https://ec.europa.eu/eurostat/statisticsexplained/pdfscache/14970.pdf

Franco, J., y Borras, S.M. Jr. (Coords.) (2015). Informe de acaparamiento de tierras de Europa. Fundación Mundubat, SAT- Sindicato Obreros del Campo y COAG (Coordinadora de Organizaciones Agrarias y Ganaderas) junto a la Vía Campesina Europa y la Red Hands off the Land. GERTU SL. Recuperado de Informe: "Acaparamiento de Tierras en Europa» - Mundubat

García-Llorente, M., Martín-López, B., Iniesta-Arandia, I., López-Santiago, C.A., y Montes, C. (2012). The role of multi-functionality in social preferences toward semi-arid rural landscapes: an ecosystem service approach. Environmental Science \& Policy, 19-20, 136-146. doi: https://doi.org/10.1016/j. envsci.2012.01.006 
García-Llorente, M., Pérez-Ramírez, I., Sabán de la Portilla, C., Haro, C., Benito, A. (2019). Agroecological strategies for reactivating the agrarian sector: the case of Agrolab in Madrid. Sustainability, 11(4), 1181. doi: https://doi.org/10.3390/ su11041181

García-Llorente, M., Rossignoli, C.M., Di lacovo, F., y Moruzzo, R., (2016) Social farming in the promotion of social-ecological sustainability in rural and periurban areas. Sustainability, 8(12), 1238. doi: https://doi.org/10.3390/su8121238

Goldman, R.L., Thompson, B.H., y Daily, G.C. (2007). Institutional incentives for managing the landscape: Inducing cooperation for the production of ecosystem services. Ecological Economics, 64(2), 333-343. doi: https://doi.org/10.1016/j. ecolecon.2007.01.012

González, D. (2007). Aproximación etnoarqueológica a los vaqueiros d'lazada: un grupo ganadero trashumante de la montaña astuariana. Arqueoweb, 8(2). Recuperado de https://webs.ucm.es/info/ arqueoweb/pdf/8-2/gonzalezalvarez.pdf

González de Molina, M. (2013). Agroecology and Politics. How to get sustainability? About the necessity for a political agroecology. Agroecology and Sustainable Food Systems, 37(1), 45-59. Recuperado de (PDF) Agroecology and Politics. How To Get Sustainability? About the Necessity for a Political Agroecology (researchgate.net)

González de Molina, M., Soto, D., Gúzman, G., Infante, J., Aguilera, E., Vila, J., y García, R. (2019). Historia de la Agricultura Española. Desde una perspectiva biofísica 1900-2010. Madrid, España: Series Estudios 183, Ministerio de Agricultura, Pesca y Alimentación. Recuperado de (PDF) Historia de la agricultura española desde una perspectiva biofísica, 1900-2010 (researchgate.net)

Gordon, L.J., Finlayson, C.M., y Falkenmark, M. (2010) Managing water in agriculture for food production and other ecosystem services. Agricultural Water Management, 97(4), 512-519. doi: https:// doi.org/10.1016/j.agwat.2009.03.017

Groenfeldt, D. (2006). Multifunctionality of agricultural water: looking beyond food production and ecosystem services. Irrigation and Drainage, 55(1), 73-83. doi: https://doi.org/10.1002/ird.217

Hatt, S., Sidonie, A., Brédart, D., et al., (2016). Towards sustainable food systems: the concept of agroecology and how it questions current research practices. A review. Biotechnologie, Agronomie, Société et Environnement, 20(S 1), 215-224. doi: https://doi.org/10.25518/1780-4507.12997

Horrigan, L., Lawrence, R.S., y Walker, P. (2002). How sustainable agriculture can address the environmental and human health harms of industrial agriculture. Environmental Health Perspectives, 110(5), 445-456. doi: https://doi.org/10.1289/ ehp.02110445

Infante, J., y González De Molina, M. (2013). Sustainable de-growth. in agriculture and food: An agro-ecological perspective on Spain's agri-food system (year 2000). Journal of Cleaner Production, 38, 27-35. doi: https://doi.org/10.1016/j. jclepro.2011.03.018

Kroma, M.M.K. (2006). Organic farmer networks: Facilitating learning and innovation for sustainable agriculture. Journal of Sustainable Agriculture, 28(4), 5-28. doi: https://doi.org/10.1300/ J064v28n04_03

Lamine, C., Bui, S., y Ollivier, G. (2015). Pour une approche systémique et pragmatique de la transition écologique des systèmes agri-alimentaires/ Towards a systemic and pragmatic approach of ecological transitions within agrifood systems/ Para una aproximación sistémica y pragmática de la transición. Cahiers de Recherche Sociologique, 58, 95-117. doi: https://doi.org/10.7202/ 1036208ar

Laurent, C., Cerf, M., y Labarthe, P. (2006) Agricultural extension services and market regulation: Learning from a comparison of six EU countries. J. The Journal of Agricultural Education and Extension 12, 5-16. doi: https://doi.org/10.1080/ 13892240600740787

Leco, F., Pérez, A., y Mateos, A. (2012). Capital social y desarrollo en el Valle del Jerte el papel del asociacionismo agrario. En R. Baena, et al. (Eds.), Investigando en rural (p. 655-662). Navarra, España: Ulzama Ediciones.

Mata, R., y Sanz, C. (coord.). (2003). Atlas de los Paisajes de España. Madrid, España: Ministerio de Medio Ambiente.

Matson, P.A., Parton, W.J., Power, A.G., y Swift, M.J. (1997). Agricultural Intensification and Ecosystem Properties. Science, 277, 504-509. doi: https:// doi.org/10.1126/science.277.5325.504 
Meinzen-Dick, R., H. Markelova, J. Hellin, y S. Dohrn. (2009). Collective action for smallholder market access. Food Policy, 34 (1), 1-59. doi: https://doi. org/10.1016/j.foodpol.2008.10.001

Méndez, R. (2016). Renovar economías urbanas en crisis: un debate actual sobre la innovación. Desenvolvimento Regional em debate, 6, (3), 4-31.

Méndez, R. (2018). Prácticas económicas alternativas y nuevas dinámicas urbanas. Los grupos de consumo agroecológico. En J. Delgadillo, y J. Sanz (Ed.), Sistemas agroalimentarios locales de proximidad. Contextos rururbanos en México y España (pp. 21-42). Ciudad de México: Universidad Nacional Autónoma de México.

Méndez, R., y Monteserín O. (2017). Redes alimentarias alternativas en grandes ciudades: los mercados de productores agrarios en Madrid. Cuadernos Geográficos, 56(1), 193-216.

Michelini, J. J., Méndez, R., y Abad, L. D. (2017). Movilización social y alternativas alimentarias en áreas urbanas: los grupos de consumo agroecológico en Madrid. Ciudad y Territorio - Estudios Territoriales, XLIX (194)(1),679-698.

Ministerio de Agricultura, Pesca y Alimentación-MAPA. (2017). Pliego de condiciones de la Indicación Geográfica Protegida "Ternera. Asturias. Recuperado de http://movil.asturias.es/Asturias/descargas/ P D F _ T E M A S / A g r i c u l t u r a / Alimentaci\%C3\%B3n/I.G.\%20P.\%20\%20\%20 Ternera\%20Asturiana.pdf

Monteserín, O., y Méndez, R. (2019). Prácticas económicas alternativas en Madrid: una aproximación. En S. H. José Luis (Ed.), Espacios y prácticas económicas alternativas en las ciudades españolas (pp. 147-164). España.

Moulaert, F., Martinelli,F., Swyngedouw, E. y Gonzales, S. (2005). Towards alternative model(s) of local innovation. Urban Studies, 42, (11), 19691990. doi: https://doi.org/10.1080/0042098050 0279893

Navarro, A. (2015). Planes de gestión en fincas agrarias con acuerdos de custodia. En J. I. Gómez, C. Yacamán, y A. Navarro (Ed.), El Mercado de la Custodia Agraria. Una propuesta para la certificación de los acuerdos de custodia del territorio (pp. 28-35). Madrid, España: Heliconia s.coop. mad y Fundación Biodiversidad.
Neumeier, S. (2012). Why do Social Innovations in Rural Development Matter and Should They be Considered More Seriously in Rural Development Research? - Proposal for a Stronger Focus on Social Innovations in Rural Development Research. Sociologia Ruralis, 52(1), 48-69. doi: https://doi.org/10.1111/j.1467-9523.2011. 00553.x

Neumeier, S. (2017). Social innovation in rural development: identifying the key factors of success. Geographical Journal, 183(1), 34-46. doi: https:// doi.org/10.1111/geoj.12180

OECD (2013). Providing Agri-Environmental Public Goods through Collective Action; OECD Publishing: Paris, France; ISBN 978-92-64-19720-6. Recuperado de: https://www.oecd.org/environment/ providing-agri-environmental-public-goodsthrough-collective-action-9789264197213-en. htm

Opdam, P., Coninx, I., Dewulf, A., Steingröver, E., Vos, C., y van der Wal, M. (2016). Does information on landscape benefits influence collective action in landscape governance? Current Opinion in Environmental Sustainability, 18, 107-114. doi: https://doi.org/10.1016/j.cosust.2015.12.006

Oteros-Rozas, E., Ravera, F., y García-Llorente, M. (2019). How Does Agroecology Contribute to the Transitions towards Social-Ecological Sustainability? Sustainability 11, 4372. doi: https://doi. org/10.3390/su11164372

Rodríguez, F., y Martínez, L. (2009). Paisajes singulares de Asturias. ERÍA, 78-79, 125-138.

Rodríguez, S. L., Peterson, M. N., Cubbage, F. W., Sills, E. O., y Bondell, H. D. (2018). What is private land stewardship? Lessons from agricultural opinion leaders in North Carolina. Sustainability ), 10(2). doi: https://doi.org/10.3390/su10020297

Ryan Isakson, S. (2014). Food and finance: the financial transformation of agro-food supply chains. Journal of Peasant Studies, 41(5), 749-775. doi: https://doi.org/10.1080/03066150.2013.874340

Sánchez, J. L. (2009). Redes Alimentarias Alternativas: Concepto, Tipología y Adecuación. Boletín de la Asociación de Geógrafos Españoles, 49, 185-208.

Sánchez, J. L., y Espinosa, A. (2020). ¿Alternativa o adaptación? Los grupos de consumo de alimentos ecológicos en el área urbana de Alicante. Scripta Nova, Revista Electrónica de Geografía y 
Ciencias Sociales, 24 (638). doi: https://doi. org/10.1344/sn2020.24.27056

Sevilla, E., y Woodgate, G. (2013). Agroecología: Fundamentos del pensamiento social agrario y teoría sociológica. Agroecología, 8(2), 27-34.

Schippers, P., van der Heide, C. M., Koelewijn, H. P., Schouten, M. A. H., Smulders, R. M. J. M., Cobben, M. M. P., y Verboom, J. (2014). Landscape diversity enhances the resilience of populations, ecosystems and local economy in rural areas. Landscape Ecology, 30(2), 193-202. doi: https://doi.org/10.1007/s10980-014-0136-6

Stallman, H.R. (2011). Ecosystem services in agriculture: Determining suitability for provision by collective management. Ecological Economics, 71, 131-139. doi: https://doi.org/10.1016/j. ecolecon.2011.08.016

Swagemakers, P., Domínguez García, M. D., Milone, P., Ventura, F., y Wiskerke, J. S. C. (2019). Exploring cooperative place-based approaches to restorative agriculture. Journal of Rural Studies, 68, 191-199. doi: https://doi.org/10.1016/j. jrurstud.2018.12.003

Swinton, S.M., Lupi, F., Robertson, G.P., y Hamilton, S.K. (2007). Ecosystem services and agriculture: cultivating agricultural ecosystems for diverse benefits. Ecological Economics, 64 (2), 245-252. doi: https://doi.org/10.1016/j.ecolecon.2007.09.020

Tittonell, P. (2014). Ecological intensification of agriculture-sustainable by nature. Current Opinion. Environmental Sustainability, 8, 53-61. doi: https://doi.org/10.1016/j.cosust.2014.08.006

Thompson, G. F. (2003). Between hierarchies and markets: The logic and limits of network forms of organization. New York: Oxford University Press. doi: 10.1093/acprof:oso/9780198775270.001. 0001

Tilman, D. (1999). Global environmental impacts of agricultural expansion: The need for sustainable and efficient practices. Proceedings of the National Academy os Sciences of the United States of America, 96, 5995-6000. doi: https://doi.org/ 10.1073/pnas.96.11.5995

Verburg, P.,Crossman, N., Ellis, E. C., Heinimann, A., Hostert, P., Mertz, O., ... Zhen, L. (2015). Land system science and sustainable development of the earth system: A global land project perspective. Anthropocene, 12, 29-41. doi: https://doi. org/10.1016/j.ancene.2015.09.004

Vialatte, A., Barnaud, C., Blanco, J., Ouin, A., Choisis, J. P., Andrieu, E., ... Sirami, C. (2019). A conceptual framework for the governance of multiple ecosystem services in agricultural landscapes. Landscape Ecology, 34(7), 1653-1673. doi: https://doi. org/10.1007/s10980-019-00829-4

Wibbelmann, M., Schmutz, U., Wright, J., Udall, D., Rayns, F., Kneafsey, M., Trenchard, L., Bennett, J. y Lennartsson, M. (2013). Mainstreaming Agroecology: Implications for Global Food and Farming Systems. Centre for Agroecology and Food Security Discussion Paper. Coventry: Centre for Agroecology and Food Security. Recuperado de http://www. fao.org/agroecology/database/detail/ en/c/455332/

Yacamán, C., Mata, O., y Matarán, A. (2020a). Los sistemas territoriales de innovación social para mejorar la viabilidad de la agricultura periurbana. En J. Farinós Dasí, J. Escribano, M. P. Peñarrubia, y S. Asins (Ed.), Desafíos y oportunidades de un mundo en transición; una interpretación desde la Geografía (pp.317-332). Valencia, España: Servicios de Publicaciones de la Universitat de València.

Yacamán, C., Sanz, E., y Mata, R. (2020b). Agricultura periurbana y planificación territorial. De la protección al proyecto agrourbano. Valencia, España: Publicaciones de la Universidad de Valencia, Colección Desarrollo Territorial.

Yacamán, C.; García-Llorente, M.; Gutiérrez-Briceño, I., Fernández, M., y Benito, A. (2020c). Co-Diseño de soluciones contractuales innovadoras orientadas a potenciar la producción agroecológica y la conservación de bienes públicos ambientales. VIII Congreso Internacional de Agroecología. Universidad de Vigo. 1, 2 y 3 de julio 2020.

Zhang, W., Ricketts, T.H., Kremen, C., Carney, K., y Swinton, S.M. (2007). Ecosystem services and dis-services to agriculture. Ecological Economics., 64, 253-260. doi: https://doi.org/10.1016/j.ecolecon. 2007.02.024 